\title{
Synthesis and Characterization of Poly(tetramethyl-1,4- silphenylenesiloxane) Derivatives with Oxyethylene Substituent on Phenylene Moiety
}

\author{
Nobukatsu Nemoto(®), Yoshie Watanabe, Jun Umemiya, Yumiko Otomo \\ Department of Materials Chemistry and Engineering, College of Engineering, Nihon \\ University, Tamura-machi, Koriyama, Fukushima 963-8642, Japan \\ E-mail: nemoto@ chem.ce.nihon-u.ac.jp; Fax: +81-24-956-8812
}

Received: 10 April 2006 / Revised version: 16 June 2006 / Accepted: 29 June 2006 Published online: 21 July 2006 - C) Springer-Verlag 2006

\begin{abstract}
Summary
Novel poly(tetramethyl-1,4-silphenylenesiloxane) derivatives having 2-methoxyethoxy or 2-(2-methoxyethoxy)ethoxy substituents at both 2- and 5-positions on phenylene moieties were synthesized and characterized by differential scanning calorimetry and thermogravimetry analyses. Poly(tetramethyl-1,4-silphenylenesiloxane) derivatives were obtained by condensation polymerization of the corresponding disilanol derivatives, i.e., 1,4-bis(dimethylhydroxysilyl)-2,5-bis(2methoxyethoxy)benzene and 1,4-bis(dimethylhydroxysilyl)-2,5-bis[2-(2-methoxyethoxy)ethoxy]benzene, which were prepared by the Grignard reaction using chlorodimethylsilane and the corresponding dibromobenzene derivatives followed by the hydrolyses, catalyzed by palladium on charcoal. The introduction of 2methoxyethoxy groups on the phenylene moiety made the melting point high, compared with poly(tetramethyl-1,4-silphenylenesiloxane); however, that of 2-(2methoxyethoxy)ethoxy groups made it low, indicating the longer oxyethylene moiety induced the lowering of the melting point. There were no significant differences in the thermostabilities of both present polymers, suggesting the length of oxyethylene moiety would not affect the thermostability, though the introduction of polar oxyethylene group onto the phenylene moiety induced a decline of thermostability.
\end{abstract}

\section{Introduction}

Poly(tetramethyl-1,4-silphenylenesiloxane) is a representative polymer where a thermally stable aromatic moiety is incorporated into the polysiloxane backbone. Polysiloxanes have been well-known to exhibit the particular characteristics, such as flexibility of the main chain, low glass transition temperature, hydrophobicity based on alkyl side chain, thermostability, stability against atomic oxygen, and physiological inertness $[1,2]$. The incorporation of thermally stable aromatics into the polysiloxane backbone could presumably improve their good properties, especially the thermostability [3].

On the other hand, poly(dimethylsiloxane-tetramethyl-1,4-silphenylenesiloxane) derivatives have been used as stationary phases for gas chromatography capillary 
columns [4] due to their excellent thermostabilities and good partitioning properties. The thermostabilities and partitioning properties of stationary phases have been known to depend on the chemical structures of polymers used as stationary phases [4]. Therefore, poly(dimethylsiloxane-tetramethyl-1,4-silphenylenesiloxane) derivatives having substituents on the phenylene moiety are expected to exhibit the different thermostabilities and partitioning properties from poly(dimethylsiloxane-tetramethyl1,4-silphenylenesiloxane). Generally, poly(tetramethyl-1,4-silphenylenesiloxane) can be obtained by condensation polymerization of disilanol monomers, as represented by the method of Merker and Scott [5]. Since the preparation of the disilanol monomers with various aromatics was reported by Beck et al [6], there have been many reports on the synthesis of poly(tetramethyl-1,4-silphenylenesiloxane) derivatives [3], including block copolymers [7], graft copolymers [8], and alternating copolymers with dimethylsiloxane units [9]. Unfortunately, there have been limited number of reports on poly(tetramethylsilphenylenesiloxane) derivatives having substituents on the phenylene moieties such as tetramethyl-substituted [6], perfluoro-substituted [10], and trifluoromethyl-substituted [11] phenylene moieties.

On the other hand, poly(ethyleneoxide) has been used as polar stationary phases for gas chromatography capillary columns. Thus, we intend to introduce the 2methoxyethoxy or 2-(2-methoxyethoxy)ethoxy moiety, which is considered to be the analogous moiety of poly(ethyleneoxide), onto the phenylene moiety of poly(tetramethyl-1,4-silphenylenesiloxane).

From these points of view, we report here the preparation of novel poly(tetramethyl1,4-silphenylenesiloxane) derivatives having 2-methoxyethoxy (P1) or 2-(2methoxyethoxy)ethoxy (P2) substituents at both 2- and 5-positions on the phenylene moieties obtained by condensation polymerization of 1,4-bis(dimethylhydroxysilyl)2,5-bis(2-methoxyethoxy)benzene (M1) or 1,4-bis(dimethylhydroxysilyl)-2,5-bis[2(2-methoxyethoxy)ethoxy]benzene (M2), as shown in Scheme 1. The present paper also describes the results of thermal characterization of the obtained polymers using differential scanning calorimetry (DSC) and thermogravimetry (TG) analyses.

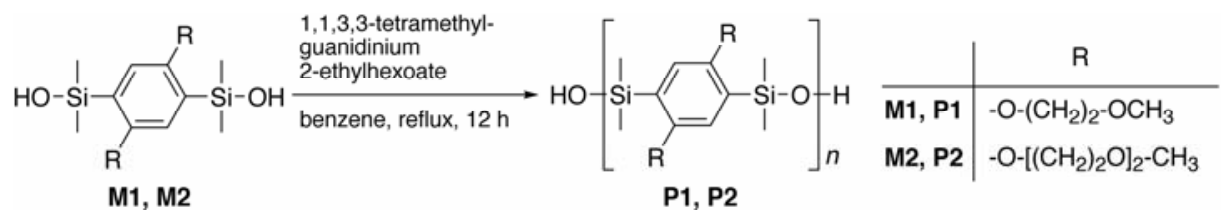

Scheme 1. Synthesis of poly[tetramethyl-2,5-bis(2-methoxyethoxy)-1,4-silphenylenesiloxane] (P1) and poly\{tetramethyl-2,5-bis[2-(2-methoxyethoxy)ethoxy]-1,4-silphenylenesiloxane $\}$ (P2)

\section{Experimental Part}

\section{Materials}

2,5-Dibromohydroquinone (1) was prepared by the bromination of hydroquinone (KANTO KAGAKU) using bromine (KANTO KAGAKU) in acetic acid [12]. 2Methoxyethyl 4-toluenesulfonate and 2-(2-methoxyethoxy)ethyl 4-toluenesulfonate were prepared by the reaction of 4-toluenesulfonyl chloride (Tokyo Kasei Kogyo Co., Inc.) with 2-methoxyethanol and 2-(2-methoxyethoxy)ethanol (KANTO KAGAKU), respectively [13]. Magnesium, potassium hydroxide, ethanol (KANTO KAGAKU), 
chlorodimethylsilane (Acros organics), and 5\% palladium on charcoal (Wako Pure Chemical Industries, Ltd.) were commercially available and used as received. 1,1,3,3Tetramethylguanidinium 2-ethylhexoate was obtained from the equimolar mixture of 1,1,3,3-tetramethylguanidine and 2-ethylhexanoic acid (Tokyo Kasei Kogyo Co., Inc.). Benzene and tetrahydrofuran (THF) (Wako Pure Chemical Industries, Ltd.) were used after distillation over sodium. The purity of all synthesized low molecularweight compounds was confirmed to be over $99 \%$ from GC analysis.

\section{Measurements}

${ }^{1} \mathrm{H}$ and ${ }^{13} \mathrm{C}$ NMR spectra were recorded on a Bruker AVANCE 400F spectrometer in deuterated chloroform $\left(\mathrm{CDCl}_{3}\right)$ or dimethylsulfoxide $\left(\left(\mathrm{CD}_{3}\right)_{2} \mathrm{SO}\right)$ at ambient temperature. IR spectra were measured on a Perkin-Elmer Spectrum One FT-IR spectrometer. Melting points were measured on a RIGAKU ThermoPlus DSC 8230 at a heating or cooling rate of $10^{\circ} \mathrm{C} / \mathrm{min}$ under a nitrogen flow rate of $10 \mathrm{~mL} / \mathrm{min}$. Thermogravimetry (TG) was performed on a RIGAKU ThermoPlus TG8110 at a heating rate of $10^{\circ} \mathrm{C} / \mathrm{min}$ under a nitrogen atmosphere. Number-average $\left(M_{\mathrm{n}}\right)$ and weight-average $\left(M_{\mathrm{w}}\right)$ molecular weights were determined by size-exclusion chromatography (SEC) using a SHOWA DENKO Shodex GPC-101 system and polystyrene gel columns (a pair of Shodex GPC LF-804) eluted with THF using a calibration curve of polystyrene standards.

\section{Preparation of $2 a$ and $2 b$}

Under a dry argon atmosphere, 2,5-dibromohydroquinone $(1,12.86 \mathrm{~g}, 48.0 \mathrm{mmol})$ and potassium hydroxide $(8.14 \mathrm{~g}, 145 \mathrm{mmol})$ were dissolved in ethanol $(100 \mathrm{~mL})$. To this solution, 2-methoxyethyl 4-toluenesulfonate $(33.27 \mathrm{~g}, 144 \mathrm{mmol})$ was added dropwise and the reaction mixture was refluxed for $10 \mathrm{~h}$. Then, the reaction mixture was poured into the mixture of chloroform $(200 \mathrm{~mL})$ and $\mathrm{NH}_{4} \mathrm{Cl}$ aqueous solution (100 $\mathrm{mL}$ ). The organic layer was washed with $\mathrm{NH}_{4} \mathrm{Cl}$ aqueous solution, dried over anhydrous $\mathrm{MgSO}_{4}$, and filtered. The filtrate was concentrated under reduced pressure. The residue was recrystallized from the mixed solvent of ethyl acetate/hexane to afford 1,4-dibromo-2,5-bis(2-methoxyethoxy)benzene (2a) as colorless crystals with the yield of $75.4 \%$ (13.91 g, $36.2 \mathrm{mmol})$. M.p.: $101^{\circ} \mathrm{C}$. ${ }^{1} \mathrm{H} \mathrm{NMR}\left(400 \mathrm{MHz}, \mathrm{CDCl}_{3}\right.$, ppm): $\delta 3.47$ (s, 6H, $\left.-\mathrm{OCH}_{3}\right), 3.77\left(\mathrm{t}, J=4.4 \mathrm{~Hz}, 4 \mathrm{H},-\mathrm{CH}_{2}-\mathrm{O}-\mathrm{CH}_{3}\right), 4.11(\mathrm{t}, J=4.4 \mathrm{~Hz}$, $\left.4 \mathrm{H}, \mathrm{Ph}-\mathrm{O}-\mathrm{CH}_{2}-\right), 7.15$ (s, $2 \mathrm{H}$, phenylene protons). ${ }^{13} \mathrm{C} \mathrm{NMR}\left(100 \mathrm{MHz}, \mathrm{CDCl}_{3}, \mathrm{ppm}\right)$ : $\delta 59.4\left(-\mathrm{OCH}_{3}\right), 70.1\left(-\mathrm{OCH}_{2}\right), 70.9\left(-\mathrm{OCH}_{2}\right), 111.5$ (phenylene carbons), 119.2 (phenylene carbons), 150.4 (phenylene carbons). IR $\left(\mathrm{KBr}, \mathrm{cm}^{-1}\right): 1216$ (aromatic ether), 1124 (aliphatic ether).

1,4-Dibromo-2,5-bis[2-(2-methoxyethoxy)ethoxy]benzene (2b) was prepared by the similar method as the preparation of $\mathbf{2 a}$ using 2-(2-methoxyethoxy)ethyl 4toluenesulfonate as the raw material. Yield: $62.2 \%$ as colorless crystals. M.p.: $63^{\circ} \mathrm{C}$. ${ }^{1} \mathrm{H}$ NMR $\left(400 \mathrm{MHz}, \mathrm{CDCl}_{3}, \mathrm{ppm}\right): \delta 3.40\left(\mathrm{~s}, 6 \mathrm{H},-\mathrm{OCH}_{3}\right), 3.56-3.60(\mathrm{~m}, 4 \mathrm{H},-\mathrm{O}-$ $\left.\left(\mathrm{CH}_{2}\right)_{2}-\mathrm{OCH}_{3}\right), 3.74-3.79\left(\mathrm{~m}, 4 \mathrm{H},-\mathrm{O}-\left(\mathrm{CH}_{2}\right)_{2}-\mathrm{OCH}_{3}\right), 3.88(\mathrm{t}, \mathrm{J}=4.4 \mathrm{~Hz}, 4 \mathrm{H}, \mathrm{Ph}-\mathrm{O}-$ $\mathrm{CH}_{2}-\mathrm{CH}_{2}-\mathrm{O}-$ ), 4.13 (t, $\left.\mathrm{J}=4.4 \mathrm{~Hz}, 4 \mathrm{H}, \mathrm{Ph}-\mathrm{O}-\mathrm{CH}_{2}-\mathrm{CH}_{2}-\mathrm{O}-\right), 7.16$ (s, 2H, phenylene protons). $\left.{ }^{13} \mathrm{C} \mathrm{NMR} \mathrm{(100} \mathrm{MHz,} \mathrm{CDCl}_{3}, \mathrm{ppm}\right): \delta 59.1\left(-\mathrm{OCH}_{3}\right), 69.6\left(-\mathrm{OCH}_{2}\right), 70.2$ $\left(-\mathrm{OCH}_{2}-\right), 71.0 \quad\left(-\mathrm{OCH}_{2}\right), \quad 72.0 \quad\left(-\mathrm{OCH}_{2}\right), 111.4$ (phenylene carbons), 119.1 (phenylene carbons), 150.3 (phenylene carbons). IR $\left(\mathrm{KBr}, \mathrm{cm}^{-1}\right): 1216$ (aromatic ether), 1146, 1131, 1102 (aliphatic ether). 


\section{Preparation of $3 a$ and $\mathbf{3 b}$}

Under a dry argon atmosphere, $\mathbf{2 a}(6.00 \mathrm{~g}, 15.6 \mathrm{mmol})$ and chlorodimethylsilane (4.43 $\mathrm{g}, 46.8 \mathrm{mmol})$ in dry THF $(80 \mathrm{~mL})$ were added dropwise to magnesium $(0.868 \mathrm{~g}, 35.7$ $\mathrm{mmol})$ in dry THF $(80 \mathrm{~mL})$ at $60^{\circ} \mathrm{C}$. The reaction mixture was stirred at $60^{\circ} \mathrm{C}$ for $24 \mathrm{~h}$ and poured into the mixture of diethyl ether $(100 \mathrm{~mL})$ and $0.5 \mathrm{~mol} / \mathrm{L} \mathrm{HCl}$ aqueous solution $(100 \mathrm{~mL})$. The organic layer was washed with saturated $\mathrm{NaHCO}_{3}$ aqueous solution, dried over anhydrous $\mathrm{MgSO}_{4}$, and filtered. The filtrate was concentrated under reduced pressure. The residue was dissolved in the mixed solvent of hexane/ethyl acetate and purified by silica gel chromatography eluted with the mixed solvent of hexane/ethyl acetate (vol. ratio $2: 1, \mathrm{R}_{\mathrm{f}}$ value: 0.78 ). The collected fraction of the purified material was concentrated under reduced pressure. The residue was recrystallized from the mixed solvent of hexane/ethyl acetate to afford 1,4bis(dimethylsilyl)-2,5-bis(2-methoxyethoxy)benzene (3a) as colorless crystals with the yield of $60.1 \%(3.21 \mathrm{~g}, 9.37 \mathrm{mmol})$. M.p.: $68^{\circ} \mathrm{C}$. ${ }^{1} \mathrm{H}$ NMR $\left(400 \mathrm{MHz}, \mathrm{CDCl}_{3}\right.$, ppm): $\delta 0.34\left(\mathrm{~d}, J=3.6 \mathrm{~Hz}, 12 \mathrm{H}, \mathrm{Si}-\left(\mathrm{CH}_{3}\right)_{2}\right), 3.43\left(\mathrm{~s}, 6 \mathrm{H},-\mathrm{OCH}_{3}\right), 3.73(\mathrm{t}, J=4.4 \mathrm{~Hz}$, $4 \mathrm{H},-\mathrm{CH}_{2}-\mathrm{O}-\mathrm{CH}_{3}$ ), 4.09 (t, J=4.4 Hz, 4H, Ph-O-CH $2^{-}$), 4.37 (sept, J=3.6 Hz, 2H, Si$\mathrm{H}), 6.91$ (s, 2H, phenylene protons). ${ }^{13} \mathrm{C} \mathrm{NMR}\left(100 \mathrm{MHz}, \mathrm{CDCl}_{3}, \mathrm{ppm}\right): \delta-4.84$ (Si$\left.\left(\mathrm{CH}_{3}\right)_{2}\right), 58.0\left(-\mathrm{OCH}_{3}\right), 66.8\left(-\mathrm{OCH}_{2}-\right), 70.2\left(-\mathrm{OCH}_{2}\right), 116.8$ (phenylene carbons), 127.5 (phenylene carbons), 156.5 (phenylene carbons). IR ( $\left.\mathrm{KBr}, \mathrm{cm}^{-1}\right): 2114(\mathrm{Si}-\mathrm{H})$, 1205 (aromatic ether), 1110 (aliphatic ether).

1,4-Bis(dimethylsilyl)-2,5-bis[2-(2-methoxyethoxy)ethoxy]benzene (3b) was prepared by the similar method as the preparation of $\mathbf{3 a}$ using $\mathbf{2} \mathbf{b}$ as the raw material. Yield: $64.3 \%$ as colorless liquid. ${ }^{1} \mathrm{H}$ NMR (400 $\left.\mathrm{MHz}, \mathrm{CDCl}_{3}, \mathrm{ppm}\right): \delta 0.33(\mathrm{~d}, J=3.6 \mathrm{~Hz}$, $\left.12 \mathrm{H}, \mathrm{Si}-\left(\mathrm{CH}_{3}\right)_{2}\right), 3.39\left(\mathrm{~s}, 6 \mathrm{H},-\mathrm{OCH}_{3}\right), 3.54-3.59\left(\mathrm{~m}, 4 \mathrm{H},-\mathrm{O}-\left(\mathrm{CH}_{2}\right)_{2}-\mathrm{OCH}_{3}\right), 3.68-3.72$ (m, 4H, -O- $\left.\left(\mathrm{CH}_{2}\right)_{2}-\mathrm{OCH}_{3}\right), 3.83$ (t, $\left.\mathrm{J}=4.4 \mathrm{~Hz}, 4 \mathrm{H}, \mathrm{Ph}-\mathrm{O}-\mathrm{CH}_{2}-\mathrm{CH}_{2}-\mathrm{O}-\right), 4.12$ (t, J=4.4 $\mathrm{Hz}, 4 \mathrm{H}, \mathrm{Ph}-\mathrm{O}-\mathrm{CH}_{2}-\mathrm{CH}_{2}-\mathrm{O}-$ ), 4.36 (sept, $J=3.6 \mathrm{~Hz}, 2 \mathrm{H}, \mathrm{Si}-\mathrm{H}$ ), 6.90 (s, 2H, phenylene protons). ${ }^{13} \mathrm{C} \mathrm{NMR}\left(100 \mathrm{MHz}, \mathrm{CDCl}_{3}, \mathrm{ppm}\right): \delta-4.86\left(\mathrm{Si}-\left(\mathrm{CH}_{3}\right)_{2}\right), 57.9\left(-\mathrm{OCH}_{3}\right), 66.7$ $\left(-\mathrm{OCH}_{2}-\right), 68.8\left(-\mathrm{OCH}_{2}-\right), 69.5\left(-\mathrm{OCH}_{2-}\right), 70.8\left(-\mathrm{OCH}_{2}-\right), 116.6$ (phenylene carbons), 127.3 (phenylene carbons), 156.3 (phenylene carbons). IR $\left(\mathrm{KBr}, \mathrm{cm}^{-1}\right): 2114(\mathrm{Si}-\mathrm{H})$, 1203 (aromatic ether), 1109 (aliphatic ether).

\section{Preparation of Monomers}

Under a dry argon atmosphere, 3a $(3.07 \mathrm{~g}, 8.96 \mathrm{mmol})$ in dry THF (1.7 $\mathrm{mL})$ was added dropwise to $5 \%$-Pd on $\mathrm{C}(0.018 \mathrm{~g})$ with $\mathrm{H}_{2} \mathrm{O}(0.42 \mathrm{~g}, 23 \mathrm{mmol})$ in THF (5.0 $\mathrm{mL})$ in an ice bath. The reaction mixture was stirred at ambient temperature for $2 \mathrm{~h}$ and filtered. The filtrate was concentrated under reduced pressure and the residue was recrystallized from benzene to afford 1,4-bis(dimethylhydroxysilyl)-2,5-bis(2methoxyethoxy)benzene (M1) as colorless crystals with the yield of $40.2 \%(1.35 \mathrm{~g}$, $3.60 \mathrm{mmol})$. M.p.: $102^{\circ} \mathrm{C}$. ${ }^{1} \mathrm{H}$ NMR $\left(400 \mathrm{MHz},\left(\mathrm{CD}_{3}\right)_{2} \mathrm{SO}, \mathrm{ppm}\right): \delta 0.22(\mathrm{~s}, 12 \mathrm{H}, \mathrm{Si}-$ $\left.\left(\mathrm{CH}_{3}\right)_{2}\right), 3.29\left(\mathrm{~s}, 6 \mathrm{H},-\mathrm{OCH}_{3}\right), 3.63\left(\mathrm{t}, \mathrm{J}=4.4 \mathrm{~Hz}, 4 \mathrm{H},-\mathrm{CH}_{2}-\mathrm{O}-\mathrm{CH}_{3}\right), 3.99$ (t, $J=4.4 \mathrm{~Hz}$, $\left.4 \mathrm{H}, \mathrm{Ph}-\mathrm{O}-\mathrm{CH}_{2^{-}}\right), 5.67$ (s, 2H, Si-OH), 6.98 (s, 2H, phenylene protons). ${ }^{13} \mathrm{C} \mathrm{NMR}$ $\left(100 \mathrm{MHz},\left(\mathrm{CD}_{3}\right)_{2} \mathrm{SO}, \mathrm{ppm}\right): \delta 1.31\left(\mathrm{Si}-\left(\mathrm{CH}_{3}\right)_{2}\right), 58.3\left(-\mathrm{OCH}_{3}\right), 67.3\left(-\mathrm{OCH}_{2}-\right), 71.0$ $\left(-\mathrm{OCH}_{2}-\right), 117.0$ (phenylene carbons), 130.6 (phenylene carbons), 156.7 (phenylene carbons). IR ( $\left.\mathrm{KBr}, \mathrm{cm}^{-1}\right): 3400(-\mathrm{OH}), 1207$ (aromatic ether), 1127, 1102 (aliphatic ether).

1,4-Bis(dimethylhydroxysilyl)-2,5-bis[2-(2-methoxyethoxy)ethoxy]benzene (M2) was prepared by the similar method as the preparation of $\mathbf{M 1}$ using $\mathbf{3 b}$ as the raw material. 
Yield: $39.8 \%$ as colorless crystals recrystallized from the mixed solvent of toluene/hexane. M.p.: $61^{\circ} \mathrm{C}$. ${ }^{1} \mathrm{H}$ NMR $\left(400 \mathrm{MHz},\left(\mathrm{CD}_{3}\right)_{2} \mathrm{SO}, \mathrm{ppm}\right): \delta 0.22(\mathrm{~s}, 12 \mathrm{H}$, $\left.\mathrm{Si}-\left(\mathrm{CH}_{3}\right)_{2}\right), 3.23\left(\mathrm{~s}, 6 \mathrm{H},-\mathrm{OCH}_{3}\right), 3.42-3.48\left(\mathrm{~m}, 4 \mathrm{H},-\mathrm{O}-\left(\mathrm{CH}_{2}\right)_{2}-\mathrm{OCH}_{3}\right), 3.54-3.59(\mathrm{~m}$, $\left.4 \mathrm{H},-\mathrm{O}-\left(\mathrm{CH}_{2}\right)_{2}-\mathrm{OCH}_{3}\right), 3.70$ (t, $\left.\mathrm{J}=4.4 \mathrm{~Hz}, 4 \mathrm{H}, \mathrm{Ph}-\mathrm{O}-\mathrm{CH}_{2}-\mathrm{CH}_{2}-\mathrm{O}-\right), 3.98$ (t, J=4.4 Hz, $4 \mathrm{H}$, Ph-O- $\left.\mathrm{CH}_{2}-\mathrm{CH}_{2}-\mathrm{O}-\right), 5.65$ (s, 2H, Si-OH), 6.98 (s, 2H, phenylene protons). ${ }^{13} \mathrm{C}$ NMR $\left(100 \mathrm{MHz},\left(\mathrm{CD}_{3}\right)_{2} \mathrm{SO}, \mathrm{ppm}\right): \delta 1.31\left(\mathrm{Si}-\left(\mathrm{CH}_{3}\right)_{2}\right), 58.3\left(-\mathrm{OCH}_{3}\right), 67.4\left(-\mathrm{OCH}_{2}-\right)$, $69.5\left(-\mathrm{OCH}_{2}-\right), 69.8\left(-\mathrm{OCH}_{2}\right), 71.5\left(-\mathrm{OCH}_{2}\right), 116.9$ (phenylene carbons), 130.6 (phenylene carbons), 156.7 (phenylene carbons). IR (KBr, cm$\left.{ }^{-1}\right): 3493(-\mathrm{OH}), 1205$ (aromatic ether), 1139, 1128, 1103 (aliphatic ether).

\section{Condensation Polymerization}

Under a dry atmosphere, 1,1,3,3-tetramethylguanidinium 2-ethylhexoate $(0.02 \mathrm{~g})$ was added to M1 $(0.210 \mathrm{~g}, 0.56 \mathrm{mmol})$ dissolved in dry benzene $(12.5 \mathrm{~mL})$, and the reaction mixture was refluxed for $12 \mathrm{~h}$. The reaction mixture was poured into methanol $(100 \mathrm{~mL})$ to isolate poly[tetramethyl-2,5-bis(2-methoxyethoxy)-1,4silphenylenesiloxane] (P1) as white precipitates with the yield of $81.0 \%(0.162 \mathrm{~g})$. ${ }^{1} \mathrm{H}$ NMR (400 MHz, $\left.\mathrm{CDCl}_{3}, \mathrm{ppm}\right): \delta 0.38\left(\mathrm{~s}, 12 \mathrm{H}, \mathrm{Si}-\left(\mathrm{CH}_{3}\right)_{2}\right), 3.35\left(\mathrm{~s}, 6 \mathrm{H},-\mathrm{OCH}_{3}\right)$, $3.63\left(\mathrm{t}, J=4.4 \mathrm{~Hz}, 4 \mathrm{H},-\mathrm{CH}_{2}-\mathrm{O}-\mathrm{CH}_{3}\right), 3.96\left(\mathrm{t}, \mathrm{J}=4.4 \mathrm{~Hz}, 4 \mathrm{H}, \mathrm{Ph}-\mathrm{O}-\mathrm{CH}_{2^{-}}\right), 7.03(\mathrm{~s}, 2 \mathrm{H}$, phenylene protons). ${ }^{13} \mathrm{C}$ NMR $\left(100 \mathrm{MHz}, \mathrm{CDCl}_{3}, \mathrm{ppm}\right): \delta 1.67\left(\mathrm{Si}-\left(\mathrm{CH}_{3}\right)_{2}\right), 58.8$ $\left(-\mathrm{OCH}_{3}\right), 67.1\left(-\mathrm{OCH}_{2}-\right), 71.2\left(-\mathrm{OCH}_{2}-\right), 116.8$ (phenylene carbons), 130.0 (phenylene carbons), 156.9 (phenylene carbons). IR (KBr, $\left.\mathrm{cm}^{-1}\right)$ : 1205 (aromatic ether), 10001100 (Si-O).

Poly\{tetramethyl-2,5-bis[2-(2-methoxyethoxy)ethoxy]-1,4-silphenylenesiloxane (P2) was prepared by the similar method as the preparation of P1 using M2 as a monomer. Yield: $77.5 \%$ as colorless powders. ${ }^{1} \mathrm{H}$ NMR $\left(400 \mathrm{MHz}, \mathrm{CDCl}_{3}, \mathrm{ppm}\right.$ ): $\delta 0.40$ (s, $\left.12 \mathrm{H}, \mathrm{Si}-\left(\mathrm{CH}_{3}\right)_{2}\right), 3.35\left(\mathrm{~s}, 6 \mathrm{H},-\mathrm{OCH}_{3}\right), 3.49-3.54\left(\mathrm{~m}, 4 \mathrm{H},-\mathrm{O}-\left(\mathrm{CH}_{2}\right)_{2}-\mathrm{OCH}_{3}\right), 3.60-3.65$ $\left(\mathrm{m}, 4 \mathrm{H},-\mathrm{O}-\left(\mathrm{CH}_{2}\right)_{2}-\mathrm{OCH}_{3}\right), 3.77\left(\mathrm{t}, \mathrm{J}=4.4 \mathrm{~Hz}, 4 \mathrm{H}, \mathrm{Ph}-\mathrm{O}-\mathrm{CH}_{2}-\mathrm{CH}_{2}-\mathrm{O}-\right), 4.01(\mathrm{t}, \mathrm{J}=4.4$ $\left.\mathrm{Hz}, 4 \mathrm{H}, \mathrm{Ph}-\mathrm{O}-\mathrm{CH}_{2}-\mathrm{CH}_{2}-\mathrm{O}-\right), 7.02$ (s, $2 \mathrm{H}$, phenylene protons). ${ }^{13} \mathrm{C} \mathrm{NMR}(100 \mathrm{MHz}$, $\left.\mathrm{CDCl}_{3}, \mathrm{ppm}\right): \delta 1.78\left(\mathrm{Si}-\left(\mathrm{CH}_{3}\right)_{2}\right), 59.0\left(-\mathrm{OCH}_{3}\right), 67.1\left(-\mathrm{OCH}_{2^{-}}\right), 70.0\left(-\mathrm{OCH}_{2}-\right), 70.4$ $\left(-\mathrm{OCH}_{2}-\right), 71.9\left(-\mathrm{OCH}_{2}-\right), 116.6$ (phenylene carbons), 130.1 (phenylene carbons), 156.8 (phenylene carbons). IR (KBr, $\mathrm{cm}^{-1}$ ): 1203 (aromatic ether), 1000-1100 (Si-O).

\section{Results and Discussion}

\section{Syntheses of Monomers}

Scheme 2 shows the pathways for the syntheses of disilanol monomers M1 and M2. M1 and M2 were synthesized by the hydrolyses of the corresponding bis(dimethylsilyl)benzene derivatives (3a, $\mathbf{3 b}$ ), which had been obtained from the corresponding dibromobenzene derivatives $(\mathbf{2 a}, \mathbf{2} \mathbf{b})$ via the Grignard reactions with chlorodimethylsilane. The spectroscopic data described in the experimental part indicated the syntheses of novel monomers were achieved. As an example, ${ }^{1} \mathrm{H}$ and ${ }^{13} \mathrm{C} \mathrm{NMR}$ spectra of $\mathbf{M 2}$ are described in Figure 1. Each signal was consistently assigned as described in Figure 1. The structure of M1 was also confirmed by ${ }^{1} \mathrm{H}$ and ${ }^{13} \mathrm{C}$ NMR and IR spectroscopy. Beck et al. reported [6] that bis(dimethylhydroxysilyl)benzene derivatives were obtained by the hydrolysis of the corresponding bis(dimethylsilyl)benzene derivatives with good yields using sodium ethoxide followed by a 
treatment of buffer aqueous solution. In this study, it was confirmed that M1 could be obtained by the method of Beck et al [6] with the yield below $30 \%$. On the other hand, hydrolysis of 1,4-bis(dimethylsilyl)benzene using the metal catalyst such as 5\%$\mathrm{Pd}, \mathrm{Pt}$, or $\mathrm{Ru}$ on charcoal has been reported to afford 1,4-bis(dimethylhydroxysilyl)benzene with high yields [14]. In the present study, it was also revealed that M1 could be obtained by the hydrolysis of $\mathbf{3 a}$ using $5 \% \mathrm{Pd}$ on charcoal as a catalyst with the yield of $40 \%$. Thus, we carried out the hydrolysis of bis(dimethylsilyl)benzene derivatives using $5 \% \mathrm{Pd}$ on charcoal as a catalyst.

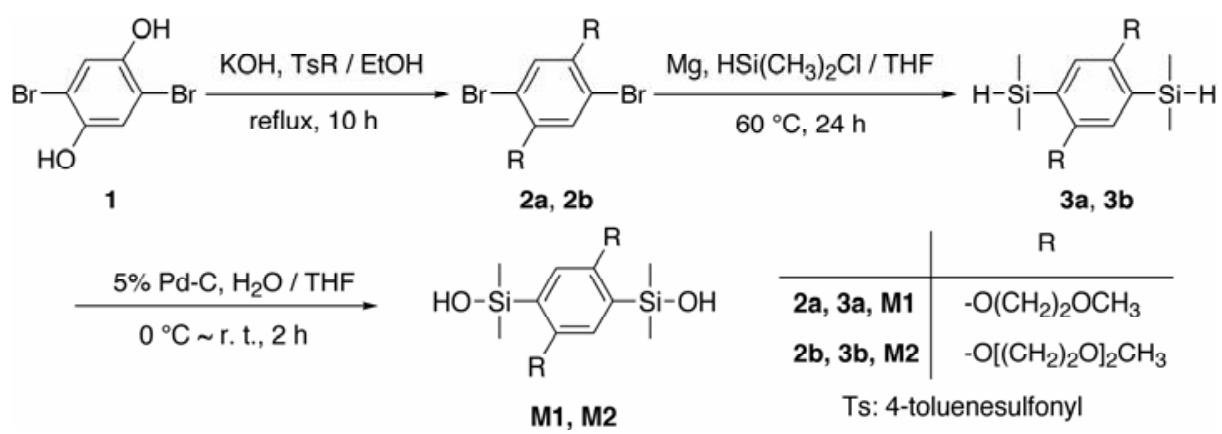

Scheme 2. Pathways for synthesis of disilanol monomers M1 and M2
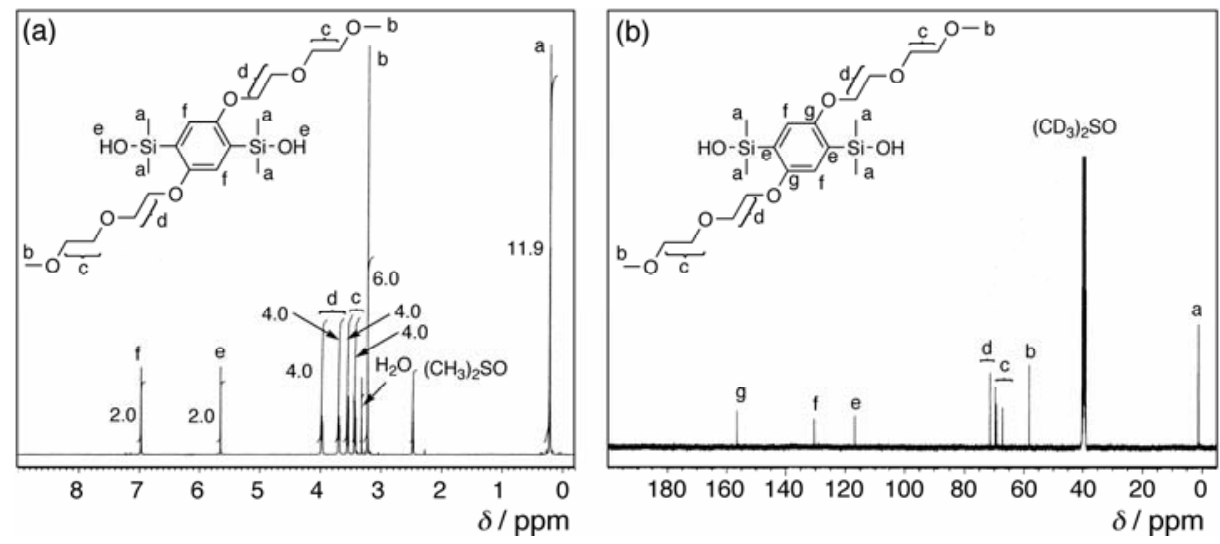

Figure 1. (a) ${ }^{1} \mathrm{H} \mathrm{NMR}$ (solvent: $\left(\mathrm{CD}_{3}\right)_{2} \mathrm{SO}, 400 \mathrm{MHz}$, numerals at signal's side are the integral values of each signal) and (b) ${ }^{13} \mathrm{C}$ NMR spectra (solvent: $\left.\left(\mathrm{CD}_{3}\right)_{2} \mathrm{SO}, 100 \mathrm{MHz}\right)$ of $\mathbf{M 2}$ at ambient temperature.

\section{Syntheses and Characterization of Polymers}

M1 and M2 underwent the condensation polymerization catalyzed by 1,1,3,3tetramethylguanidinium 2-ethylhexoate [5] to afford the corresponding poly(tetramethyl-1,4-silphenylenesiloxane) derivatives P1 and P2, respectively. Any solvents forming azeotropic mixtures with water and dissolving both monomer and the resulting polymer, such as benzene and toluene, can be used for the present polymerization. The low monomer concentration resulted in the formation of not 
polymer but the corresponding cyclic compounds. Thus, we used the minimum amount of the solvent, which dissolved both monomers and the resulting polymers. The most important factor for polymer formation seems to be the monomer concentration during the condensation polymerization. The SEC profiles of $\mathbf{P 1}$ and P2 indicated the obtained polymers were unimodal. Figure 2 shows the SEC profile of $\mathbf{P 2}$ eluted with THF as an example, indicating the polymer formation and the absence of low molecular weight species such as cyclic dimer or trimer.

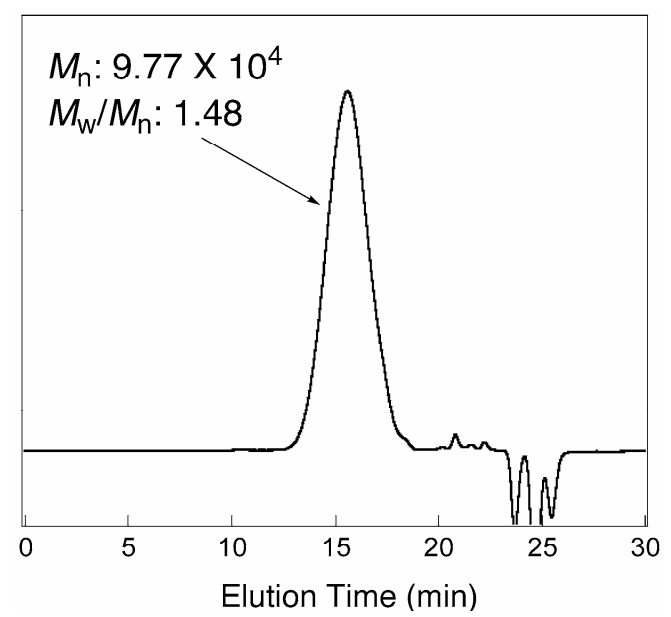

Figure 2. SEC profile of $\mathbf{P 2}$ eluted with THF.

The structures of $\mathbf{P 1}$ and $\mathbf{P 2}$ were confirmed by ${ }^{1} \mathrm{H}$ and ${ }^{13} \mathrm{C}$ NMR and IR spectroscopy. As a typical example, ${ }^{1} \mathrm{H}$ and ${ }^{13} \mathrm{C}$ NMR spectra of $\mathbf{P 2}$ are described in Figure 3. Each signal was consistently assigned as described in Figure 3.
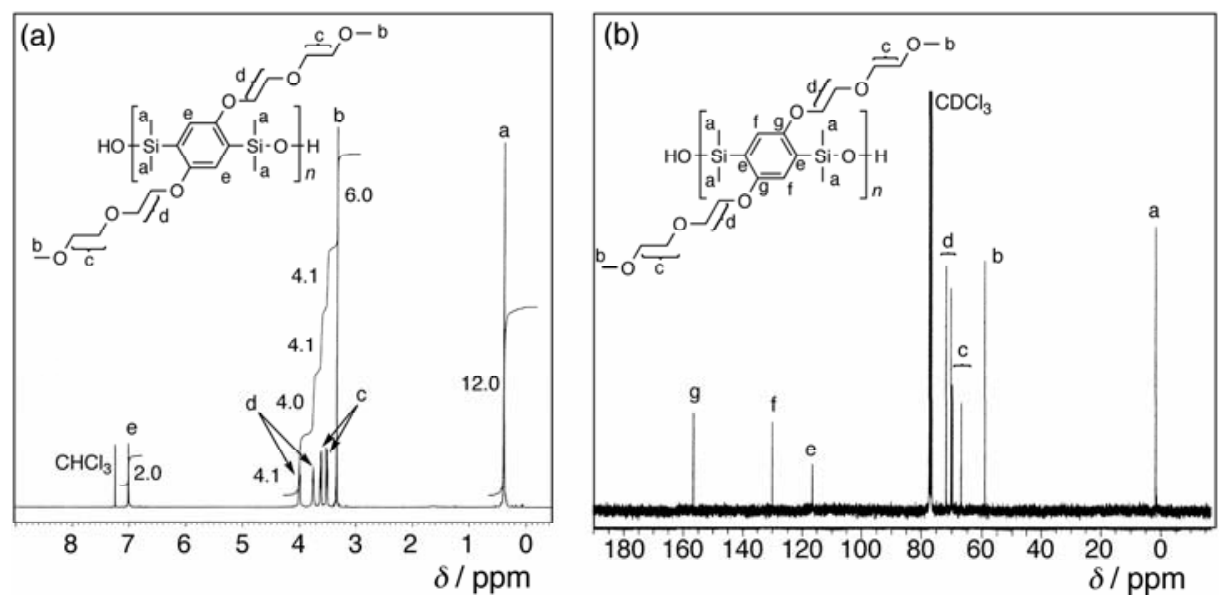

Figure 3. (a) ${ }^{1} \mathrm{H} \mathrm{NMR}$ (solvent: $\mathrm{CDCl}_{3}, 400 \mathrm{MHz}$, numerals at signal's side are the integral values of each signal) and (b) ${ }^{13} \mathrm{C}$ NMR spectra (solvent: $\mathrm{CDCl}_{3}, 100 \mathrm{MHz}$ ) of $\mathbf{P 2}$ at ambient temperature. 
The characterization of $\mathbf{P 1}$ and $\mathbf{P 2}$ is summarized in Table 1. P1 and $\mathbf{P 2}$ are soluble in common organic solvents such as THF, chloroform, dichloromethane, and toluene.

Table 1. Characterization of $\mathbf{P 1}$ and $\mathbf{P 2}$

\begin{tabular}{ccccc}
\hline Polymer & $10^{-4} M_{\mathrm{n}}{ }^{\mathrm{a})}$ & $M_{\mathrm{w}} / M_{\mathrm{n}}{ }^{\mathrm{b})}$ & $T_{\mathrm{m}}\left({ }^{\circ} \mathrm{C}\right)^{\mathrm{c})}$ & $T_{\mathrm{d} 5}\left({ }^{\circ} \mathrm{C}\right)^{\mathrm{d})}$ \\
\hline P1 & 3.77 & 1.75 & 178 & 393 \\
P2 & 9.77 & 1.48 & 98 & 389 \\
\hline
\end{tabular}

a) Number-average molecular weight estimated from SEC eluted with THF based on polystyrene standards.

b) Polydispersity index.

c) Melting point determined by DSC at a heating rate of $10^{\circ} \mathrm{C} / \mathrm{min}$ under nitrogen atmosphere.

d) Temperature at $5 \mathrm{wt} \%$ weight loss determined by TG under nitrogen atmosphere.

Figure 4 shows the DSC traces of $\mathbf{P 1}$ and $\mathbf{P 2}$ on the first cooling and second heating scans under a nitrogen atmosphere at a cooling or heating rate of $10^{\circ} \mathrm{C} / \mathrm{min}$.

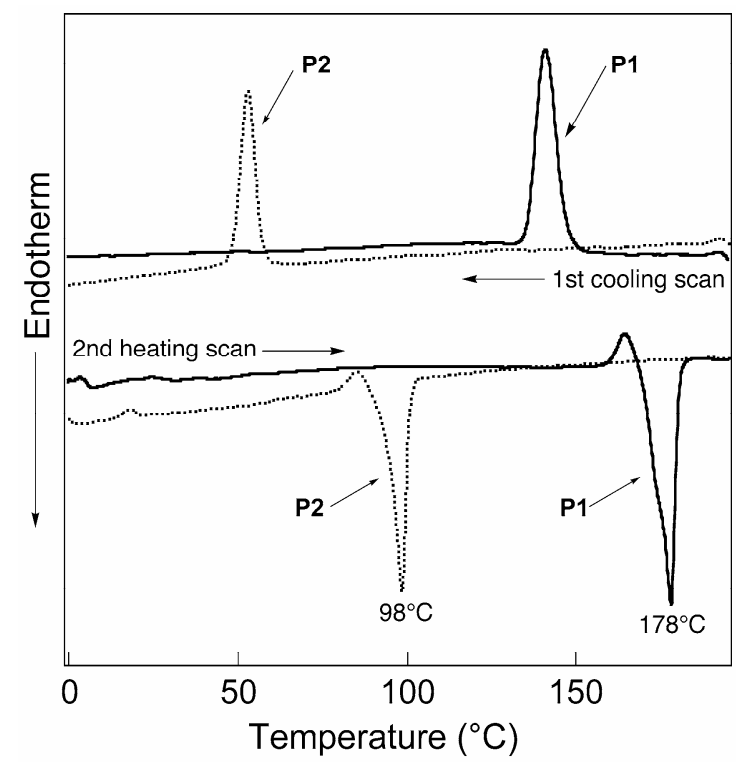

Figure 4. DSC thermograms of $\mathbf{P 1}$ (line) and $\mathbf{P 2}$ (dotted line) on a first cooling scan from $200^{\circ} \mathrm{C}$ and a second heating scan under a nitrogen flow rate of $10 \mathrm{~mL} / \mathrm{min}$ and a cooling or heating rate of $10^{\circ} \mathrm{C} / \mathrm{min}$.

The exothermic peak based on crystallization was observed on the first cooling scans from $200^{\circ} \mathrm{C}$ of both polymers after a supercooling state. Small exothermic peaks in the DSC thermograms on the second heating scans around $30^{\circ} \mathrm{C}$ for $\mathbf{P 1}$ and $20^{\circ} \mathrm{C}$ for $\mathbf{P 2}$ were observed, presumably due to the partial crystallization of the polymer. The endothermic peak based on melting clearly appeared on the second heating scans of both polymers. These findings would indicate $\mathbf{P 1}$ and $\mathbf{P 2}$ exhibit the crystallinity. 
The melting points $\left(T_{\mathrm{m}}\right.$ 's) of $\mathbf{P 1}$ and $\mathbf{P 2}$ were determined to be 178 and $98^{\circ} \mathrm{C}$, respectively, from each second heating scan; however, the glass transition temperatures $\left(T_{\mathrm{g}}\right.$ 's) of $\mathbf{P 1}$ and $\mathbf{P 2}$ were not clearly observed between -50 and $400^{\circ} \mathrm{C}$. The $T_{\mathrm{m}}$ of poly(tetramethyl-1,4-silphenylenesiloxane) $\left(M_{\mathrm{n}}: 186000, M_{\mathrm{w}} / M_{\mathrm{n}}: 1.82\right)$ prepared by condensation polymerization of 1,4-bis(dimethylhydroxysilyl)benzene in our laboratory was determined to be $130^{\circ} \mathrm{C}$ by a DSC measurement. The thermodynamic melting temperature of poly(tetramethyl-1,4-silphenylenesiloxane) has been reported to be $160^{\circ} \mathrm{C}$ by Magill et al [15]. The $T_{\mathrm{m}}$ of $\mathbf{P 1}$ was found to be higher than that of poly(tetramethyl-1,4-silphenylenesiloxane), due to the interactions between methoxyethoxy groups as well as aromatic moieties. The $T_{\mathrm{m}}$ of $\mathbf{P 2}$ is found to be lower than that of poly(tetramethyl-1,4-silphenylenesiloxane), presumably because the longer oxyethylene chains would inhibit the interactions between the bulky main-chain aromatic moieties. The length of oxyethylene moiety would induce the lowering of $T_{\mathrm{m}}$.

On the other hand, there were no significant differences in the temperatures at $5 \mathrm{wt} \%$ weight loss $\left(T_{\mathrm{d} 5}\right.$ 's) of $\mathbf{P 1}\left(393^{\circ} \mathrm{C}\right)$ and $\mathbf{P 2}\left(389^{\circ} \mathrm{C}\right)$ determined by $\mathrm{TG}$ under a nitrogen atmosphere as summarized in Table 1, indicating the length of oxyethylene group would not affect the thermostability. The $T_{\mathrm{d} 5}$ of poly(tetramethyl-1,4-silphenylenesiloxane) has been reported to be over $500^{\circ} \mathrm{C}$ [3]. The $T_{\mathrm{d} 5}$ 's of $\mathbf{P 1}$ and $\mathbf{P 2}$ were low compared with that of poly(tetramethyl-1,4-silphenylenesiloxane). This finding would be attributed to the difference in the bond energies among $\mathrm{Si}-\mathrm{O}, \mathrm{C}-\mathrm{C}$ and $\mathrm{C}-\mathrm{O}$ bondings. The bond energies of $\mathrm{C}-\mathrm{C}$ and $\mathrm{C}-\mathrm{O}$ have been reported to be 346 and 358 $\mathrm{kJ} / \mathrm{mol}$, respectively, which are lower than that of $\mathrm{Si}-\mathrm{O}(444 \mathrm{~kJ} / \mathrm{mol})$ [3]. Thus, the introduction of oxyethylene groups induces the lowering of $T_{\mathrm{d} 5}$; however, the thermostabilities of $\mathbf{P 1}$ and $\mathbf{P 2}$ are acceptable as stationary phases for gas chromatography capillary columns [4]. It would be possible to prepare the new polar stationary phases for gas chromatography capillary columns by copolymerization using M1 or M2 with poly(dimethylsiloxane).

\section{Conclusions}

The syntheses of novel poly(tetramethyl-1,4-silphenylenesiloxane) derivatives having 2-methoxyethoxy (P1) or 2-(2-methoxyethoxy)ethoxy (P2) substituent at both 2- and 5 -positions on phenylene moieties were achieved by condensation polymerization of novel disilanol derivatives, i.e., 1,4-bis(dimethylhydroxysilyl)-2,5-bis(2-methoxyethoxy)benzene (M1) and 1,4-bis(dimethylhydroxysilyl)-2,5-bis[2-(2-methoxyethoxy)ethoxy]benzene (M2), respectively. The $T_{\mathrm{m}}$ of $\mathbf{P 1}$ was higher than that of poly(tetramethyl-1,4-silphenylenesiloxane); however, that of $\mathbf{P 2}$ was lower than that of poly(tetramethyl-1,4-silphenylenesiloxane), indicating the longer oxyethylene moiety would induce the lowering of $T_{\mathrm{m}}$. There were no significant differences in the $T_{\mathrm{d} 5}$ 's of $\mathbf{P 1}$ and $\mathbf{P 2}$, which were low compared with that of poly(tetramethyl-1,4silphenylenesiloxane). The introduction of oxyethylene groups induces the decline of thermostability; however, the length of oxyethylene moiety would not affect the thermostability.

Acknowledgements. The authors would like to appreciate Mr. Yoshikazu Sato, Associate Professor in Nihon University, for performing TG analyses; and Ms. Satoko Tokiwa as well as Ms. Nami Oyama, Nihon University College of Engineering Worldwide Research Center for Advanced Engineering \& Technology (NEWCAT), for performing NMR measurements. 


\section{References}

1. Mark J E (1990) Silicon-containing polymers. In: Ziegler JM, Gordon FW (eds) Siliconbased polymer science. American Chemical Society, Washington DC (Adv Chem Ser, vol 224, pp 47-90)

2. Brook MA (2000) Silicon in organic, organometallic, and polymer chemistry (chapter 9). John Wiley \& Sons, Inc, New York

3. Dvornic PR, Lenz RW (1990) High temperature siloxane elastomers (chapter 2). Hüthig \& Wepf Verlag, Basel, Heiderberg, New York

4. Day GM, Hibberd AI, Habsuda J, Sharp GJ (2003) Thermally stable siloxane polymers for gas chromatography. In: Clarson SJ, Fitzgerald JJ, Owen MJ, Smith SD, van Dyke ME (eds) Synthesis and properties of silicones and silicone-modified materials. American Chemical Society, Washington DC (ACS Symp Ser vol 838, pp 127-136)

5. Merker RL, Scott, MJ (1964) J Polym Sci: Part A 2: 15-29

6. Beck HN, Chaffee RG (1963) J Chem Eng Data 8: 602-3

7. Nagase Y, Nakamura T, Misawa A, Ikeda K, Sekine Y (1983) Polymer 24: 457-62

8. Nagase Y, Ochiai J, Matsui K, Uchikura M (1988) Polymer 29: 740-5

9. Dvornic PR, Lenz RW (1994) Macromolecules 27: 5833-8

10. Loree LA, Brown ED (1971) US Patent, 3, 576, 020

11. Grindhal GA (1971) US Patent, 3, 576, 021

12. Pelter A, Jenkins I, Jones DE (1997) Tetrahedron 30: 10357-400

13. (a) Ouchi M, Inoue Y, Wada K, Iketani S, Hakushi T, Weber E (1987) J Org Chem 52: 2420-7 (b) Ouchi M, Inoue Y, Kanzaki T, Hakushi T (1984) J Org Chem 49: 1408-12

14. Barnes Jr GH, Daughenbaugh NE (1966) J Org Chem 31: 885-7

15. Li HM, Magill JH (1978) J Polym Sci: Polym Phys Ed 16: 1059-70 